Please do not remove this page

RMIT

UNIVERSITY

\title{
An analysis methodology for failure in postbuckling skin-stiffener interfaces
}

Orifici, Adrian; Thomson, Rodney; Herszberg, I; Weller, Tanchum; Degenhardt, Richard; Bayandor, Javid https://researchrepository.rmit.edu.au/esploro/outputs/9921861224901341/filesAndLinks?institution=61 RMIT_INST\&index=null

Orifici, A., Thomson, R., Herszberg, I., Weller, T., Degenhardt, R., \& Bayandor, J. (2008). An analysis methodology for failure in postbuckling skin-stiffener interfaces. Composite Structures, 86(1-3), 186-193. https://doi.org/10.1016/j.compstruct.2008.03.023

Document Version: Accepted Manuscript

Published Version: https://doi.org/10.1016/j.compstruct.2008.03.023

Repository homepage: https://researchrepository.rmit.edu.au (c) 2008 Elsevier Ltd. All rights reserved.

Downloaded On 2023/04/26 15:54:07 +1000 
Thank you for downloading this document from the RMIT Research Repository.

The RMIT Research Repository is an open access database showcasing the research outputs of RMIT University researchers.

RMIT Research Repository: http://researchbank.rmit.edu.au/

\section{Citation:}

Orifici, A, Thomson, R, Herszberg, I, Weller, T, Degenhardt, R and Bayandor, J 2008, 'An analysis methodology for failure in postbuckling skin-stiffener interfaces', Composite Structures, vol. 86, no. 1-3, pp. 186-193.

See this record in the RMIT Research Repository at:

http://researchbank.rmit.edu.au/view/rmit:6976

Version: Accepted Manuscript

Copyright Statement: (c) 2008 Elsevier Ltd. All rights reserved.

Link to Published Version:

http://dx.doi.org/10.1016/j.compstruct.2008.03.023 


\title{
An analysis methodology for failure in postbuckling skin-stiffener interfaces
}

\author{
A.C. Orifici ${ }^{\text {a, b, }}{ }^{*}$, R.S. Thomson ${ }^{\text {b }}$, I. Herszberg ${ }^{\text {b }}$, T. Weller ${ }^{\text {c }}$, R. Degenhardt ${ }^{\text {d }}$, J. Bayandor ${ }^{\text {e }}$ \\ ${ }^{a}$ School of Aerospace, Mechanical and Manufacturing Engineering, Royal Melbourne Institute of Technology, GPO Box 2476V, \\ Melbourne, Victoria, 3001, Australia \\ ${ }^{\mathrm{b}}$ Cooperative Research Centre for Advanced Composite Structures, 506 Lorimer Street, Fishermans Bend, Victoria, 3207, Australia \\ ${ }^{\mathrm{c}}$ Faculty of Aerospace Engineering, Israel Institute of Technology (Technion), Technion City, Haifa 32000, Israel \\ ${ }^{\mathrm{d}}$ German Aerospace Center (DLR), Institute of Composite Structures and Adaptive Systems, Lilienthalplatz 7, 38108 Braunschweig, \\ Germany \\ ${ }^{\mathrm{e}}$ The Sir Lawrence Wackett Aerospace Centre, School of Aerospace, Mechanical and Manufacturing Engineering, \\ Royal Melbourne Institute of Technology, GPO Box 2476V, Melbourne, Victoria, 3001, Australia
}

\begin{abstract}
Blade-stiffened structures have the potential to produce highly efficient structures, particularly when the large strength reserves available after structural buckling, in the postbuckling range, are exploited. In experimental tests of postbuckling stiffened structures made from fibre-reinforced composites, failure typically initiates at the interface of the skin and stiffener and leads to rapid and even explosive failure. A methodology has been developed for analysing collapse in postbuckling composite structures that involves predicting the initiation of interlaminar damage in the skin-stiffener interface. A strength-based criterion is monitored in each ply using a local model of the skin-stiffener interface cross section. For the analysis of large structures, a global analysis is first run to obtain the complete postbuckling deformation field, which is then input onto a local model using a global-local analysis technique. The coordinates of the local model can easily be moved to rapidly assess failure initiation at numerous skin-stiffener interface locations throughout the global structure. The analysis methodology is compared to experimental results for two-dimensional T-section specimens and large, fuselage-representative stiffened panels and is shown to give accurate predictions of the failure load and failure mechanisms. The use of the approach for the analysis of postbuckling composite structures has application for the design and certification of the next generation of aircraft.
\end{abstract}

Keywords: Buckling; Postbuckling; Stiffened panels; Skin-stiffener damage; COCOMAT

\section{Introduction}

In the aerospace industry the use of thin skins reinforced with blade stiffeners has led to highly efficient structures, particularly when the large strength reserves available after structural buckling, in the postbuckling range, are exploited. However, the application of postbuckling design with composite structures has been limited, as current analysis tools are not capable of accurately representing the damage mechanisms that lead to structural collapse of composites. In experimental tests of stiffened composite structures in postbuckling, failure typically initiates at the interface of the skin and stiffener. This leads to rapid and even explosive collapse

\footnotetext{
* Corresponding author. Fax +6139676 4999.

E-mail address: a.orifici@crc-acs.com.au (A.C. Orifici).
}

of the panel, as the damaged region spreads and leads to a detachment between the skin and stiffener.

The analysis and design of lightweight and safe postbuckling structures requires validated tools that can accurately predict structural collapse. The four-year European Commission Project COCOMAT (Improved MATerial Exploitation at Safe Design of COmposite Airframe Structures by Accurate Simulation of COllapse) is addressing this issue, and aims to exploit the large strength reserves of composite aerospace structures through the development of validated tools to capture the critical damage mechanisms leading to collapse [1-2]. COCOMAT is focused on the application of carbon fibre-reinforced materials in the next generation of aircraft fuselage designs. 
In this work, a methodology is presented for analysing collapse in postbuckling composite structures that involves detecting the initiation of interlaminar damage in the skin-stiffener interface. A strength-based criterion is monitored in each ply using a local model of the skinstiffener interface cross section. For the analysis of large structures, a global analysis is first run to obtain the complete postbuckling deformation field, which is then input onto a local model using a global-local analysis technique. For larger models, the coordinates of the local model can easily be moved to rapidly assess failure initiation at numerous skin-stiffener interface locations throughout the structure. The analysis methodology is compared to experimental results for two-dimensional $\mathrm{T}$-section specimens and large, fuselage-representative stiffened panels in terms of the failure load and failure mechanisms. The use of the approach for the analysis of postbuckling composite structures has application for the design and certification of the next generation of aircraft.

\section{Analysis Methodology}

A methodology was developed for capturing the collapse of composite structures due to the initiation of interlaminar damage [3-4]. The methodology is based around detecting interlaminar damage initiation using a strength-based criterion, which is applied to a model of the skin-stiffener interface at a ply-level mesh refinement. This approach is incorporated into the analysis of large structures using a two step global-local approach, in which the deformation field of the entire structure is first found with a global analysis, and is used as the boundary condition on a local skin-stiffener interface model. This methodology was implemented into the nonlinear finite element (FE) solver MSC.Marc (Marc) [5] with user subroutines, and further detail is given in the following sections.

\subsection{Initiation of Interlaminar Damage}

The initiation of interlaminar damage was predicted with a strength-based criterion, which was applied to the stresses at every element. The "degenerated Tsai" equation as given by Tong [6] was used, and is given by

$$
\left(\sigma_{\mathrm{x}} / X_{T}\right)^{2}+\left(\sigma_{\mathrm{z}} / Z_{T}\right)^{2}+\left(\tau_{\mathrm{yz}} / S_{\mathrm{yz}}\right)^{2} \geq 1,
$$

where $\sigma_{\mathrm{x}}, \sigma_{\mathrm{z}}, \tau_{\mathrm{yz}}$ and $X_{T}, Z_{T}, S_{\mathrm{yz}}$ are stresses and strengths in the longitudinal, through-thickness tensile and shear directions, respectively. In this equation, interlaminar damage is detected using a quadratic interaction of the various stress components in comparison with the respective strengths. In particular, this criterion requires the through-thickness tensile strength, $Z_{T}$, which is a difficult parameter to obtain experimentally. As a result it was assumed in this work that a composite ply was transversely isotropic, so that the transverse strength, which is more easily measured, was taken as equal to the through-thickness strength.

A range of other interlaminar damage criteria was investigated, which are summarised in a review given in Ref. [7]. It was found that in terms of the equations themselves there is not much variation between the majority of criteria. Differences between criteria include replacing the quadratic interaction with a linear, curve-fit or other type of interaction, and combining the longitudinal and through-thickness stresses and strengths in various combinations. Furthermore, all criteria are sensitive to the strength parameters, which themselves can be subject to considerable scatter in experimental characterisation tests. As a result of these considerations, only results using the above equation are shown.

The damage detection approach was implemented into Marc with the PLOTV user subroutine, which allows the definition of user-defined element output variables. The subroutine is called by every integration point at every layer of each element, at the end of every increment in a nonlinear analysis. The subroutine takes as input the element global stresses and strains, and the stresses in the element orientation direction, where the orientation system for all elements was aligned with the element through-thickness direction. Failure was deemed to occur when the average of all integration point values in an element satisfied the failure criterion.

\subsection{Global-Local Analysis}

Detection of interlaminar damage initiation at a ply level mesh refinement requires using finely detailed models of the skin-stiffener interface. Whilst this is possible for small specimens, it is clearly not appropriate for the analysis of large structures, which require coarse models focused on capturing global behaviour. This suggested the use of a two-step analysis procedure, in which the first step used a coarse shell model of the entire structure to determine the complete deformation history, and the second step applied the deformations from the first analysis to finely detailed models to predict damage initiation. In Marc, using the results from one analysis as 
the boundary conditions of another is known as a "global-local" analysis

The global-local procedure developed for analysing large postbuckling composite structures is detailed below.

- A "global" results file was generated for the complete structure using a coarse model, which in the models applied in this work consisted of thick shells and a fairly coarse meshing scheme. The incrementation of the global analysis was not important as the local analysis used interpolation between increments.

- A "local" model was created, with care that the global coordinates of the local model were identical to the global model. In this work, the local models used solid elements, which were necessary to properly link with the shell elements in the global model.

- A global-local boundary condition was created for a number of nodes in the local model. During the analysis, for every node in the local model with a global-local boundary condition, the solver searched the global result displacement field for a point on the structure with identical global coordinates (within a tolerance). The displacement history of that point was then input onto the local node, with interpolation if the global point did not lie on a global node. Though the number of local nodes that were necessary to replicate the deformation of the global crosssection was not pre-defined, in this work globallocal boundary conditions were applied on the local nodes that most closely matched nodes in the global model.

- The local analysis was run, with the user subroutine applied to predict the onset of interlaminar damage.

- The local model could then be modified to place it at another location within the global model. This was repeated a number of times in order to identify the point at which interlaminar damage was predicted to occur first in the global model. This process required an aspect of experience and judgement to avoid unnecessary runs of local analysis models. In general the global results file was inspected to determine locations of maximum deformation or stress, which typically occurred at nodal and anti-nodal lines in the structure.

\subsection{Ply Damage}

The collapse of composite structures in compression involves a range of damage mechanisms. In addition to predicting the initiation of interlaminar damage, it was important to capture the ply damage mechanisms such as matrix cracking and fibre fracture. As a result, the global analyses in this work all applied a degradation model to represent the onset and progression of ply damage. This ensured that the global analysis results incorporated the local softening effects of matrix damage, and the catastrophic failure resulting from fibre fracture.

For the ply damage degradation model, an approach based on the Hashin [8] failure criteria and stiffness reduction method of Chang and Lessard [9] was used, as summarised in Table 1 , where $\sigma_{11}, \sigma_{22}, \tau_{12}$ and $X, Y, S_{12}$ are stresses and strengths in the fibre, in-plane transverse and shear directions, $S_{23}$ is the through-thickness shear strength (assumed equal to $S_{12}$ for a transversely isotropic ply), and subscripts $T$ and $C$ refer to tension and compression. The criteria for fibre failure, matrix cracking and fibre-matrix shear failure were monitored and used to reduce the appropriate material properties to $10 \%$ upon detection of failure.

Table 1: In-plane failure criteria and property reduction

\begin{tabular}{|c|c|c|}
\hline Failure type & Criterion & $\begin{array}{l}\text { Property } \\
\text { reduced }\end{array}$ \\
\hline $\begin{array}{l}\text { Fibre, } \\
\text { tension } \\
\text { Fibre, } \\
\text { compression }\end{array}$ & $\begin{array}{l}\left(\sigma_{11}^{2} / X_{T}^{2}\right)^{\frac{1}{2}} \geq 1 \\
\left(\sigma_{11}^{2} / X_{C}^{2}\right)^{\frac{1}{2}} \geq 1\end{array}$ & $\begin{array}{l}E_{11}, E_{22}, \\
v_{12}, G_{12}, \\
G_{23}, G_{31}\end{array}$ \\
\hline $\begin{array}{l}\text { Matrix, } \\
\text { tension }\end{array}$ & $\left(\sigma_{22}^{2} / Y_{T}^{2}+\tau_{12}^{2} / S_{12}^{2}\right)^{\frac{1}{2}} \geq 1$ & \\
\hline $\begin{array}{l}\text { Matrix, } \\
\text { compression }\end{array}$ & $\left(\begin{array}{l}\frac{\sigma_{22}}{Y_{C}}\left(\frac{Y_{C}}{4 S_{23}}-1\right) \\
+\frac{\sigma_{22}^{2}}{4 S_{23}^{2}}+\frac{\sigma_{12}^{2}}{4 S_{12}^{2}}\end{array}\right)^{\frac{1}{2}} \geq 1$ & $E_{22}, v_{12}$ \\
\hline $\begin{array}{l}\text { Fibre-matrix } \\
\text { shear, } \\
\text { tension } \\
\text { Fibre-matrix } \\
\text { shear, } \\
\text { compression }\end{array}$ & $\left(\sigma_{11}^{2} / X_{C}^{2}+\sigma_{12}^{2} / S_{12}^{2}\right)^{\frac{1}{2}} \geq 1$ & $\begin{array}{c}v_{12}, G_{12} \\
G_{31}\end{array}$ \\
\hline
\end{tabular}




\section{Local Analysis Validation}

To validate the prediction of interlaminar damage, the approach was compared to experimental results for skinstiffener sections loaded with typical postbuckling deformations.

\subsection{Experimental Results}

A large number of skin-stiffener sections were manufactured at Israel Aircraft Industries and tested at the Aerospace Structures Laboratory in Technion within the COCOMAT project, as previously reported by Herszberg et al [10]. The specimens consisted of thin strips cut from a large co-cured stiffened panel to form $\mathrm{T}$-sections. Figure 1 shows the different specimen types, where specimens were manufactured with ply drop-offs in the stiffener flange as is common for aerospace structures, and without drop-offs to promote failure at the flange edge. The specimens were also cut at nominal widths of $13 \mathrm{~mm}, 25 \mathrm{~mm}$ and $35 \mathrm{~mm}$, and it was seen that the results were independent of specimen width.

The sections were loaded until failure in two separate test rigs, which aimed to simulate the symmetric and antisymmetric postbuckling loadings as shown in Figure 2. There were 71 tests in total, consisting of 35 antisymmetric tests, 28 symmetric pull tests and eight symmetric pull tests. Failure in each test was defined as the point of first load reduction, due to the initiation of damage at various locations in the specimen. This damage generally led to immediate specimen collapse, and although some specimens were capable of increased loading and showed multiple damage growth instances, in all cases the first damage instance was taken as the failure point.
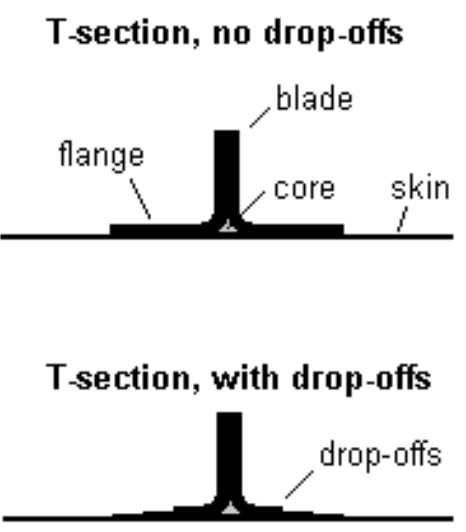

Figure 1: Skin-stiffener specimen types.
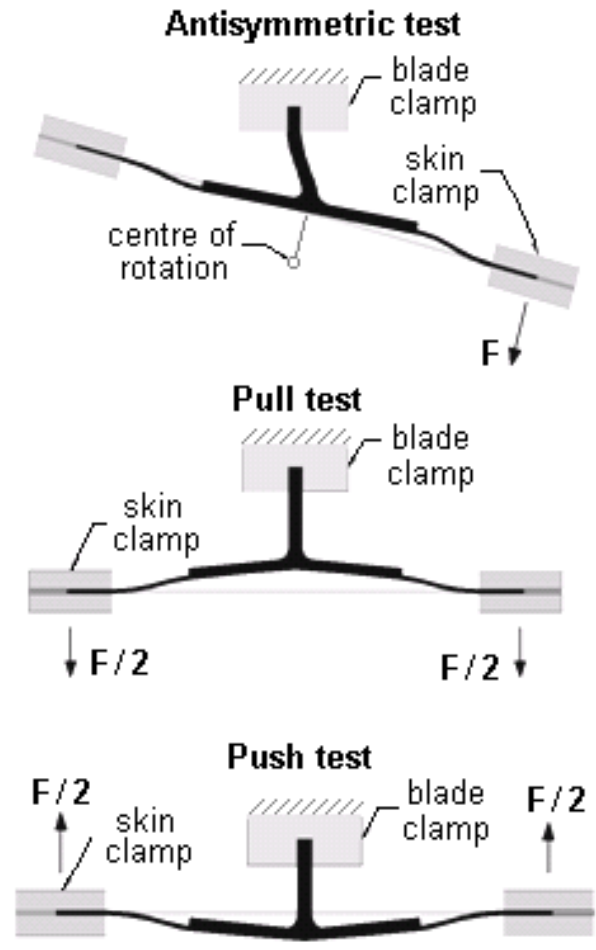

Figure 2: Schematic representation of tests simulating postbuckling deformations [10].

There were four main failure types, shown in Figure 3, which were classified according to the failure location: 1) "bend" failure in the laminate at the skin-stiffener junction; 2) "blade" failure in the stiffener blade; 3) "flange" failure at the flange edge; 4) "core" failure in the region underneath the stiffener. The failure mode was dependent on the specimen type and loading, though there was considerable variation in the test results, as evidenced by nominally identical specimens giving different failure modes, and variation in failure energies for the same failure mode. For the drop-off specimens in the pull tests bend failure was the most common mode, with only a few specimens showing stiffener or flange failure. The drop-off specimens in the antisymmetric tests showed bend and blade failures, with blade failures involving significantly lower failure energies. For the specimens without drop-offs, flange failure was the most common mode, though bend failure was also seen and for the pull tests bend failure involved failure energies lower than flange failure. All push tests specimens failed in the core region, regardless of specimen type. 
1. Bend failure

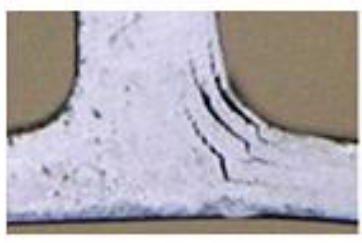

3. Flange failure

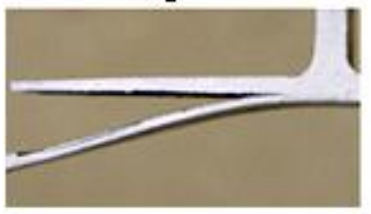

Figure 3: Skin-stiffener section failure classification.

\subsection{Numerical Analysis}

FE models were created of the antisymmetric and symmetric tests for analysis in Marc. The models used two-dimensional generalised plane strain elements, which are 6-node elements consisting of a 4-node plane strain quadrilateral element with two additional nodes shared by all elements containing the out-of-plane displacement and rotations for the entire model. The modelling approach is illustrated in Figure 4, and involved ply-level mesh refinement and definition of the local through-thickness direction. The material properties of the specimens were taken from characterisation tests on IM7/8552 unidirectional (UD) specimens, and were the average of values taken from tests in three laboratories. The stiffness data were all generally within $5 \%$ and the strength data were within $10 \%$ of the mean except for the transverse tensile strength, where the variation between data sets was up to $25 \%$ from the mean. Note that as shown in Figure 4, the triangular core region under the stiffener was defined as a central $0^{\circ}$ ply region surrounded by resin, as in the real specimens this region was filled with rolled prepreg tape during manufacture.

All models were analysed using the Marc 2005r3 nonlinear solver, with 50 increments, a convergence tolerance of 0.1 on residual forces and all other analysis parameters set to the program defaults. The analyses were run on a $2.4 \mathrm{GHz}$ Dual Core AMD Opteron processor, with run times around 60 seconds. A selection of the results is presented in Figure 5, which gives the normalised energy versus loading displacement or angle and delamination failure index at first failure, where the specimen width was used to normalise the energy results. A complete description of the results is given by Orifici et al. [3] and Orifici et al. [11].

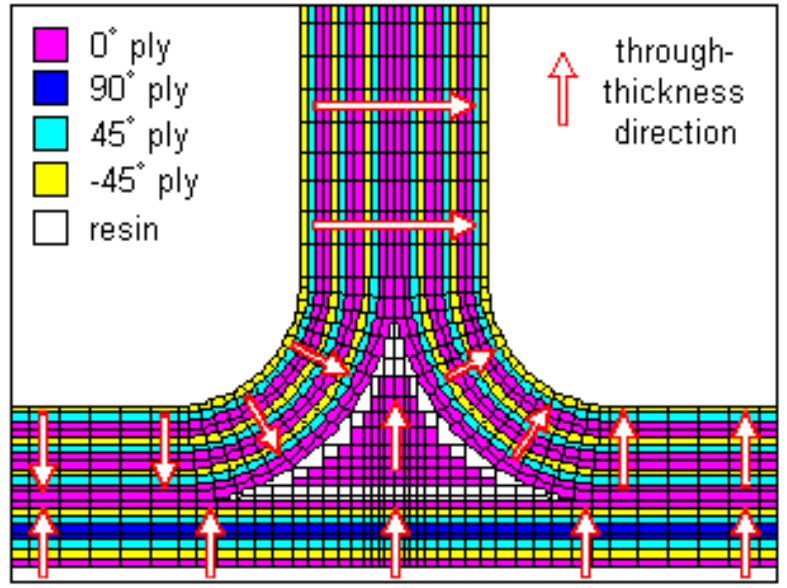

Figure 4: Skin-stiffener section modelling showing material definition and element orientations.

For the specimens with ply drop-offs experimental failure occurred in either the bend or the stiffener blade, and this was able to be predicted by the numerical approach. The numerical models predicted failure in the bend, as shown in Figure 5, which agreed well with the pull test specimens, where bend failure was the dominant mode. However, the antisymmetric tests showed both bend and blade failures, with the latter giving lower failure energies. For the specimens without ply drop-offs, the numerical models predicted failure at the flange edge. The stress concentration at the flange edge meant that the element-based failure detection was directly dependent on the element length. As a result, failure was deemed to occur when the area of failed elements exceeded $0.15 \mathrm{~mm}^{2}$. This value gave good agreement with experimental results for the antisymmetric and symmetric specimens, where flange failure was the dominant mode.

Through additional numerical analysis the reasons for nominally identical specimens showing different failure mechanisms were investigated. It was found that the failure predictions were sensitive to the strength parameters, and the scatter typically seen in material characterisation tests could promote different failure mechanisms. The specimens were also found to be sensitive to a range of parameters, including friction on the clamps and the fixity of the antisymmetric testing rig. Importantly, the failure modes that were not as well predicted using the nominal model parameters, which included blade failure due to interlaminar shear, bend failure in the pull tests and core failure in the push tests, were all considered unlikely failure mechanisms for postbuckling skin-stiffener interfaces. 

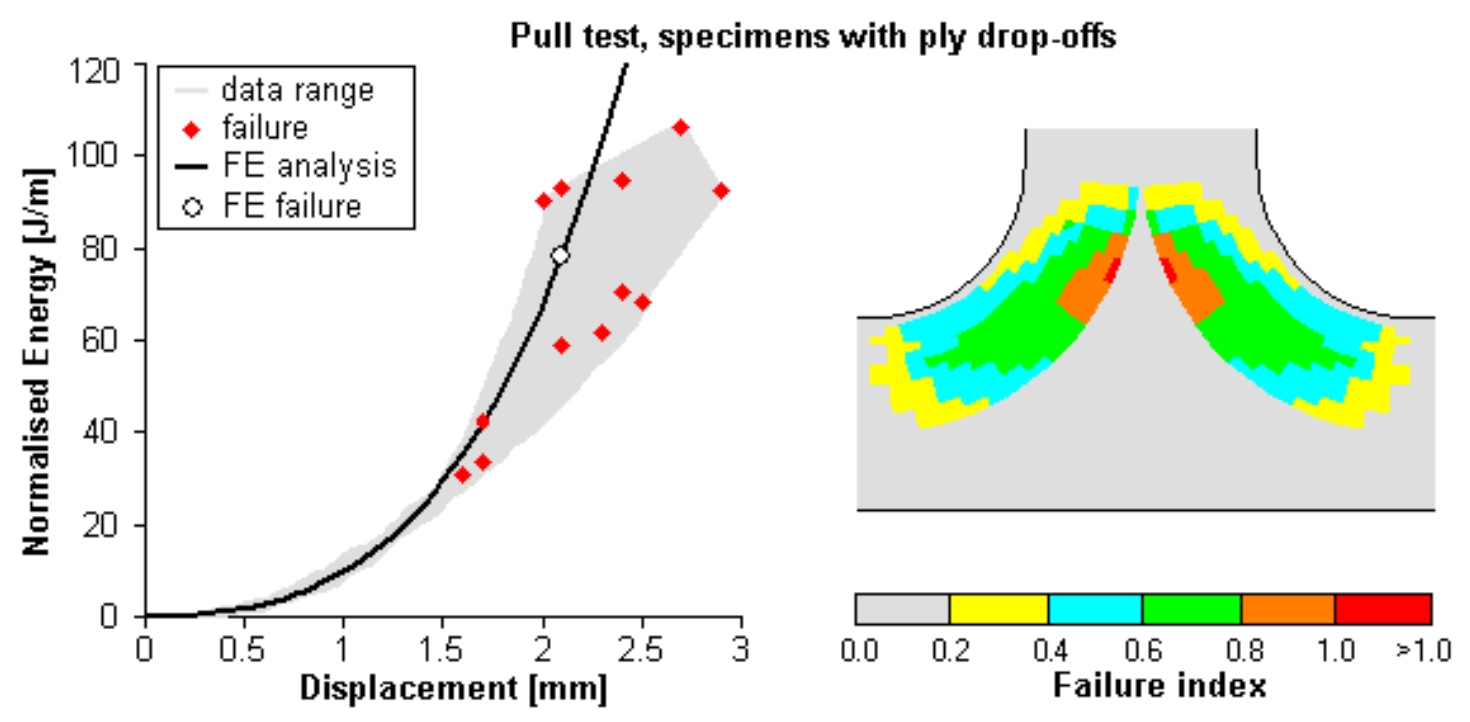

Antisymmetric tests, specimens with ply drop-offs
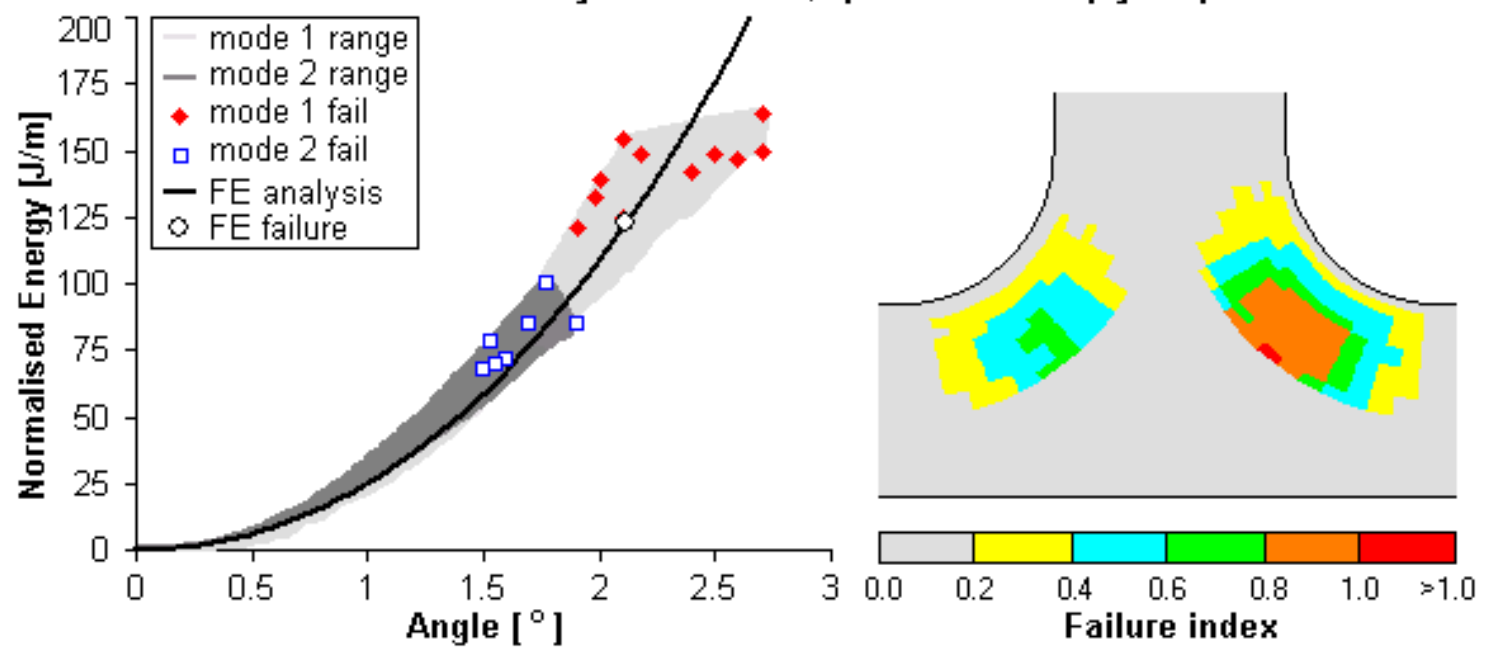

Figure 5: Selected skin-stiffener specimen results. Left: Normalised applied energy versus loading displacement. Right: delamination failure index at first failure.

\section{Global-Local Analysis Validation}

Experimental results for single- and multi-stiffener panels were used to demonstrate and validate the application of the global-local approach for predicting interlaminar damage in large structures.

\subsection{Single-Stiffener Panels}

Fuselage-representative panels consisting of a skin and single stiffener were manufactured and tested at Aernnova Engineering Solutions (Aernnova) as part of the COCOMAT project. A complete description of the experimental and numerical results for these panels is given in Ref. [12]. The panels consisted of a flat skin and secondary-bonded single stiffener, and details are given in Figure 6 and Table 2. There were two panel configurations, Design 1 (D1) and Design 2 (D2), with three panels tested for each configuration.

The panels were encased in potting to ensure an even distribution of the applied load, and were loaded in compression to collapse. Under loading, all panels developed a sequence of buckling patterns prior to collapse. Collapse was characterised by explosive failure, where the failed panels showed a wide range of damage types including fibre fracture in the stiffener, and matrix cracking and delamination around the 
interface of the skin and stiffener. However, the development of all ply damage types was instantaneous, and it was not possible to determine the sequence of damage progression.

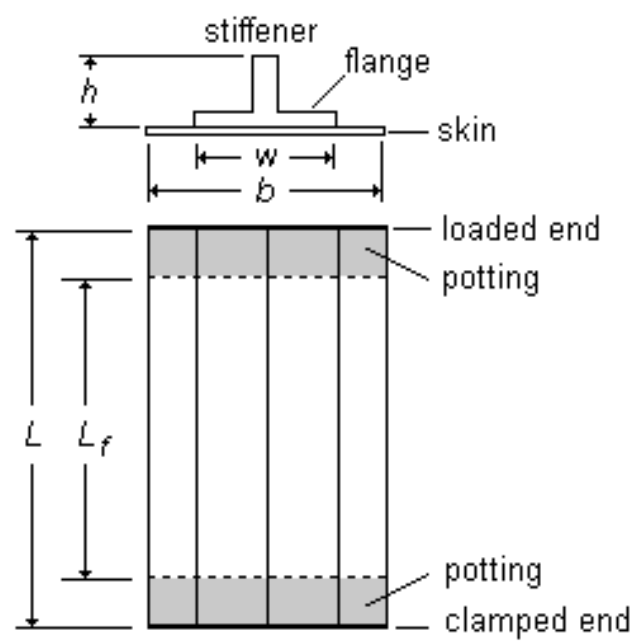

Figure 6: Single-stiffener panel geometry.

Table 2: D1 and D2 single-stiffener panel details, all dimensions in $\mathrm{mm}$

\begin{tabular}{lll}
\hline Parameter & D1 & D2 \\
\hline Total length, $L$ & 400 & 500 \\
Free length, $L_{f}$ & 300 & 400 \\
Width, $b$ & 64 & 112 \\
Skin lay-up & {$[90, \pm 45,0]_{\mathrm{S}}$} & {$[ \pm 45,0,90]_{\mathrm{S}}$} \\
Stiffener lay-up & {$\left[( \pm 45)_{3}, 0_{6}\right]_{\mathrm{s}}$} & {$\left[ \pm 45,0_{2}, 90_{2}\right]_{\mathrm{S}}$} \\
Material & $\mathrm{IM} 7 / 8552 \mathrm{UD}$ & $\mathrm{IM} 7 / 8552 \mathrm{UD}$ \\
Adhesive & FM 300 & FM 300 \\
Ply thickness, $t$ & 0.125 & 0.152 \\
Stiffener height, $h$ & 14 & 28.9 \\
Stiffener width, $w$ & 32 & 56 \\
\hline
\end{tabular}

In the numerical analysis, FE models were created for global and local analysis of both panel types. The global models consisted of a coarse and regular grid of shell elements, whilst the local models used solid brick elements at a ply-level mesh refinement, in a similar manner as the skin-stiffener section models. The material properties were taken from material characterisation tests performed within COCOMAT. All models were run in Marc v2005r3 using the nonlinear solver with a full Newton-Raphson procedure and a tolerance of 0.01 on residuals forces. Analysis results are presented below, where Figure 7 gives the load-displacement curves and
Figure 8 gives the local model deformation shape and delamination prediction.
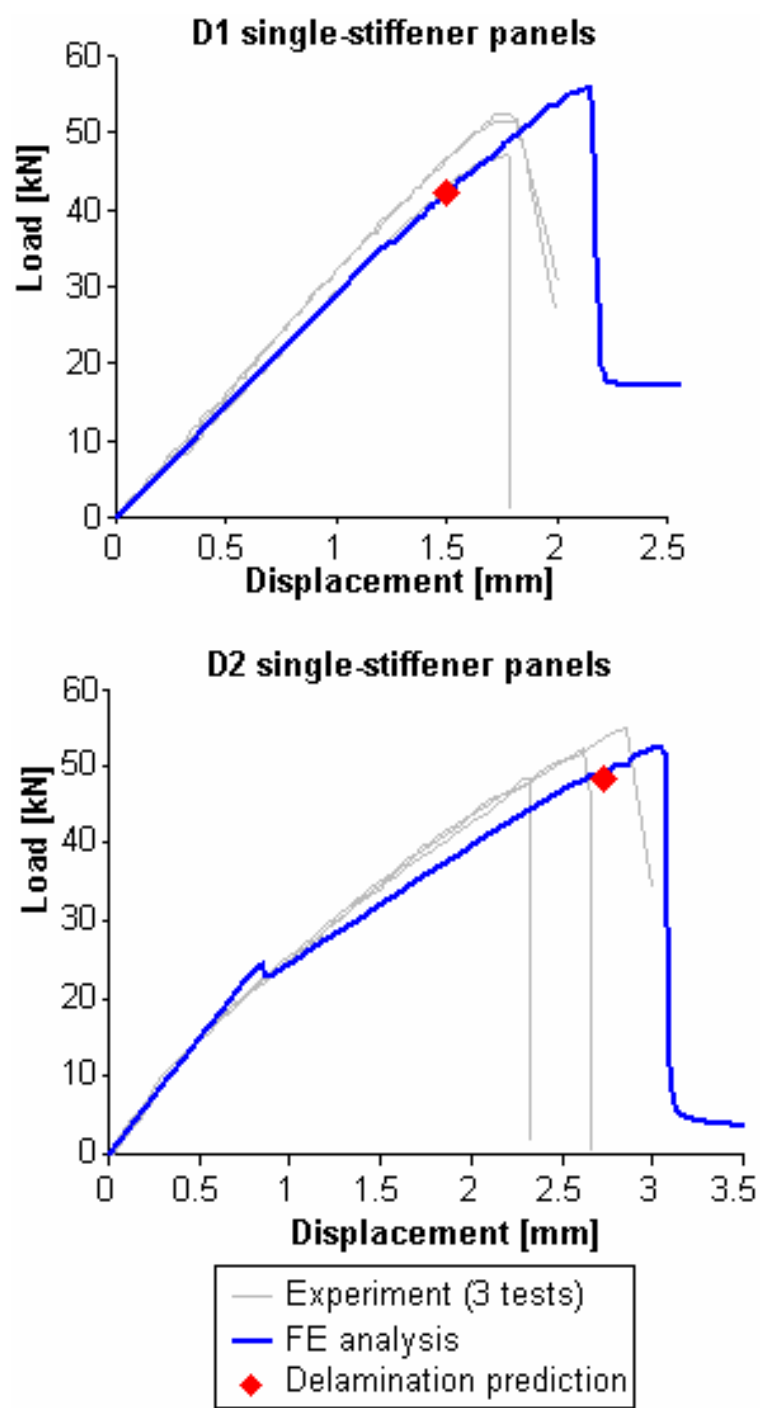

Figure 7: Single-stiffener panels, applied load versus displacement.

The stiffness of the numerical models showed close correlation with the experimental results, though the buckling pattern for the D2 model was slightly different to the experimental panel. In the global models, there was a small amount of matrix failure detected prior to the onset of fibre fracture in the stiffener, with the latter causing large reductions in the panel load. From the local model analysis, delamination was predicted to initiate in the local models prior to the onset of fibre failure. The experimental collapse values gave closer comparison with the local failure predictions, which indicated that 
D1 single-stiffener panel

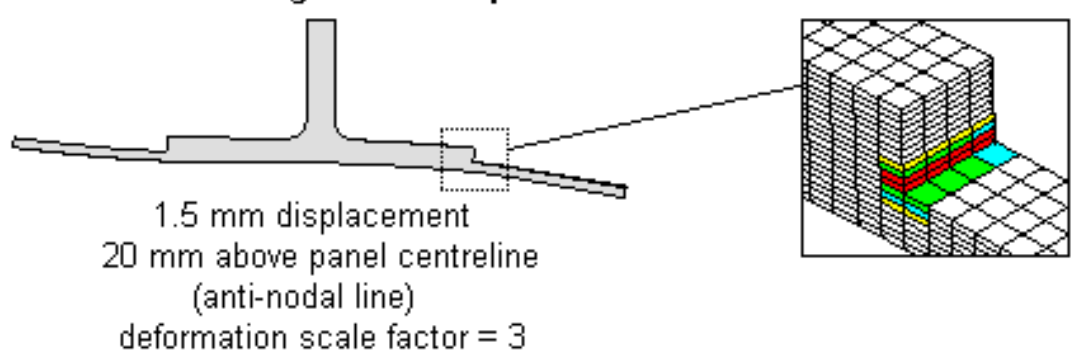

D2 single-stiffener panel

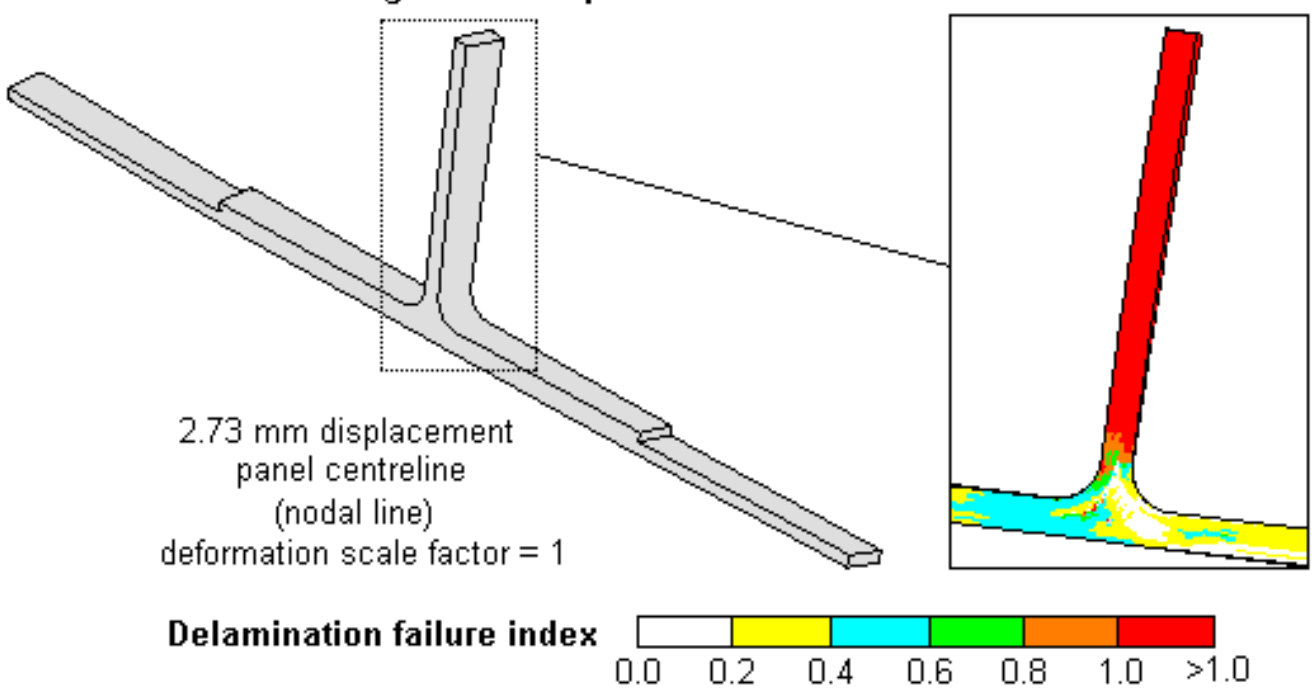

Figure 8: Single-stiffener panels, local delamination prediction.

skin-stiffener damage triggered collapse. However, this was not able to be determined in the experimental panels due to the instantaneous nature of the failure and the close correlation between collapse predictions of the global and local model.

In the D1 panel, delamination was predicted to occur at an anti-nodal line, where the buckling deformations were at a maximum, whilst the D2 panel showed delamination at a nodal line due to a high degree of twisting, as seen in Figure 8. Though the delamination and fibre fracture locations did not exactly correspond to the damage sites seen in the experiment, this was the result of the different displacement patterns and the fact that due to the periodic nature of the buckling patterns the failure indices at all of the other nodal and anti-nodal lines were very close. However, Figure 7 demonstrates that the developed analysis methodology was capable of predicting the load-carrying capacity of the panels, and the collapse predictions were realistic and within the experimental scatter of the results.

\subsection{Multi-Stiffener Panel}

A fuselage-representative multi-stiffener curved panel was manufactured by Aernnova and tested by the Institute of Composite Structures and Adaptive Systems of DLR (German Aerospace Center) as part of the COCOMAT project. A complete description of the experimental and numerical results for this panel is given in Ref. [13]. The geometry is shown in Figure 9, where the panel had a total length $(L)$ of $520 \mathrm{~mm}$, stiffener pitch $(b)$ of $156 \mathrm{~mm}$, radius $(R)$ of $1000 \mathrm{~mm}$, arc length $(W)$ of $520 \mathrm{~mm}$, and all other parameters as given for the D2 panel in Table 2. A potting consisting of epoxy resin reinforced with sand and quartz was used at the ends of both panels to ensure an even application of the end loadings and prevent lateral movement in the testing machine. A longitudinal edge restraint was also used to constrain the radial (out-of-plane) displacements along the panel side. Testing of the panel involved static loading in compression until collapse. Under compression, the panel developed a range of buckling mode shapes, which involved local buckling between the 
stiffeners leading to global buckling along the panel length. Panel collapse occurred at $1.84 \mathrm{~mm}$ axial compression, or $174 \mathrm{kN}$ applied load, and was characterised by fibre fracture in the stiffener and delaminations under all four stiffeners.

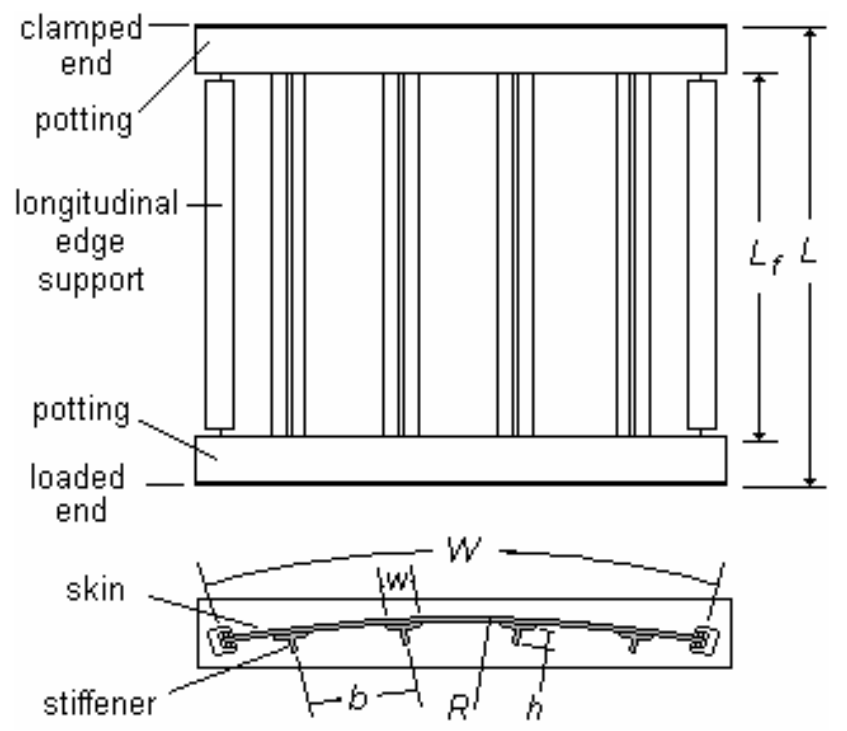

Figure 9: Multi-stiffener panel geometry.

For the numerical analysis, the global-local analysis technique described previously was applied in order to predict the collapse of the panel. The global FE model consisted of 6,032 shell elements, whilst the local model used a ply-level mesh refinement of 27,736 solid brick elements. The models were analysed in Marc v2005r3 using the nonlinear solver with a full Newton-Raphson procedure and a tolerance of 0.01 on residual forces. The load-displacement and failure predictions are given in Figure 10, Figure 11 and Figure 12. In the global model, a stable global buckling pattern of five buckling half waves developed, and collapse of the panel occurred due to fibre fracture in the stiffeners at $2.08 \mathrm{~mm}$ compression. In the local model, the critical skinstiffener interface was at the panel centre, with interlaminar damage predicted at the stiffener flange edge in the centre stiffener bay at $1.92 \mathrm{~mm}$ compression.

In comparison with experiment, the global FE model was not able to predict the exact asymmetric buckling patterns seen experimentally, and the predicted structural stiffness was lower than the experimental value, particularly in the postbuckling region. In spite of this, the panel behaviour and onset of buckling were predicted well. The predicted initiation of delamination also compared very well with the experimental collapse of the panel, though the exact location of failure was not predicted as this was dependent on the deformation. However, investigation of local models at other locations revealed that the interlaminar damage was predicted to occur at multiple locations throughout the panel within a small range of compression values up to the point at which fibre fracture occurred. These locations included anti-nodal and nodal lines, where the anti-nodal lines such as that shown in Figure 11 gave failure at the flange edge due to high peel stresses, and the nodal lines of minimum displacement failed in the region underneath the stiffener due to high shear stresses.

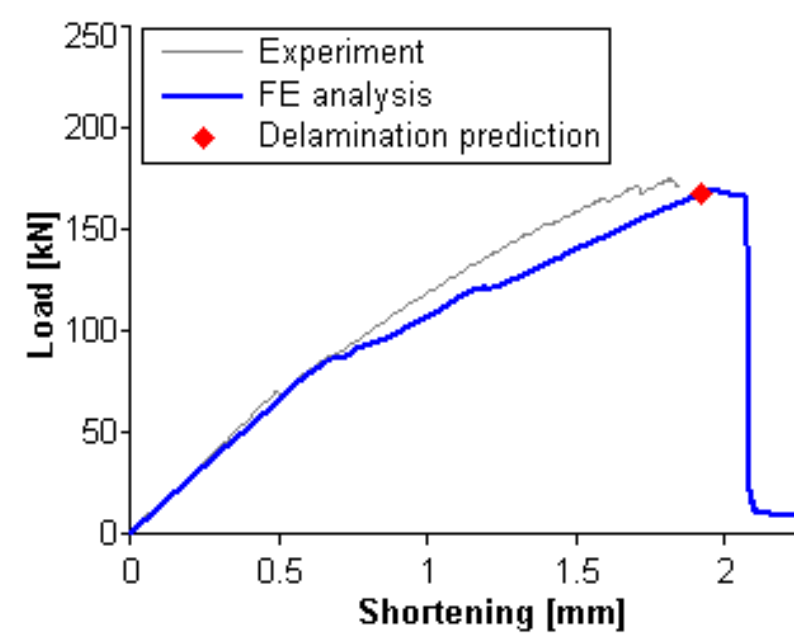

Figure 10: Multi-stiffener panel, load-shortening and delamination prediction.

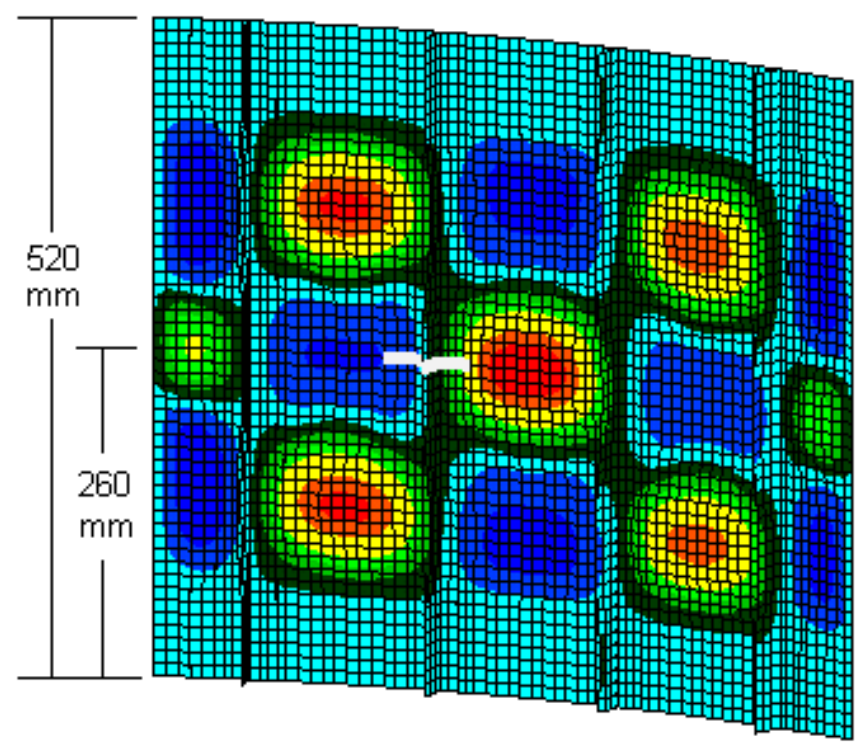

Figure 11: Multi-stiffener panel, global model with outof-plane displacement contours and local model location at $1.92 \mathrm{~mm}$ applied displacement. 


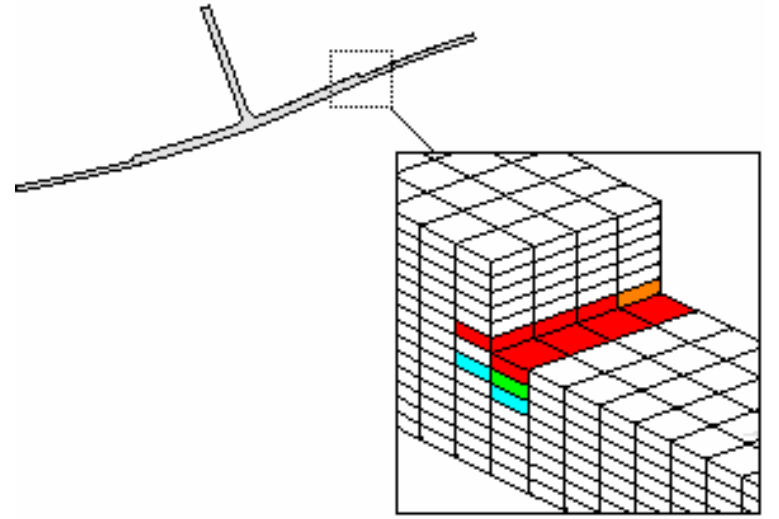

Figure 12: Multi-stiffener panel, local model at predicted onset of failure (1.92 $\mathrm{mm}$ applied displacement).

\section{Discussion}

From the results, the difficulty in validating the prediction of interlaminar damage across a range of different loading types and structural configurations was evident. For the skin-stiffener section specimens, the analysis approach was able to predict the onset of damage at the critical locations for the different loading types. However, the experimental scatter, dependence on strength data and sensitivity to different parameters illustrated the variability in these results, and suggests that further validation is required. For the global-local analyses, the initiation of interlaminar damage in the local models was close to the occurrence of fibre fracture in the global model, so that the actual mechanism leading to collapse in the experimental panel could not be clearly established. Despite this, failure was predicted in the local model before fibre fracture in the global model for all analyses, and the observation of interlaminar damage preceding panel collapse agrees with results from other researchers [14-15]. Furthermore, the analysis results indicated that there were three main mechanisms for interlaminar damage initiation: 1) interlaminar tension failure at a flange edge; 2) interlaminar tension failure in the skin-stiffener bend; 3) interlaminar shear failure in the stiffener. However, given the instantaneous nature of collapse the exact damage mechanism and location could not be determined, and detailed study of the fracture surface would be required in order to provide further validation.

For all analyses, there were a number of factors that considerably influenced the comparison with experimental results. As mentioned previously, the reliance on strength data and the assumption of transverse isotropy are critical aspects of the numerical approach, and are unavoidable for any approach. One aspect for the global models was the difficulty in accurately capturing the correct buckling mode shapes and deformation patterns which directly influences the panel behaviour and damage detection, though this is also an unavoidable aspect for any analysis. The influence of mesh density is significant, particularly for the strength-based approach in the presence of stress concentrations, and methods for mitigating this issue are given in Refs [3] and [11]. Additionally, all models used idealised geometry, such as perfectly circular flanges and straight flange edges. Though the influence of this idealisation was not investigated, previous work has indicated that geometrical variations and in particular resin overflow at the flange edge can reduce the stress concentration and promote failure in other locations in the skin-stiffener interface [3,11]. In spite of these aspects, the results demonstrated that the developed approach is capable of performing accurate and rapid analysis of postbuckling composite aerospace structures. This has clear application for the next generation of composite aircraft, as it allows the collapse of postbuckling structures to be predicted with increased reliability, leading to safer and more efficient designs.

\section{Conclusion}

A methodology was presented for predicting collapse in stiffened structures due to the initiation of interlaminar damage. The methodology monitors a strength-based criterion in each ply using finely detailed models of the skin-stiffener interface. To make this approach suitable for the analysis of large postbuckling structures, a twostep global-local approach was proposed, in which deformations from a coarse global model of a large structure are used as boundary conditions on fine local models of the skin-stiffener interface. The initiation of interlaminar damage throughout the global structure can then be rapidly assesses by modifying the local model to study different skin-stiffener locations.

The developed methodology was validated in comparison with experiment results for fuselagerepresentative composite panel designs. To study the prediction of failure in local skin-stiffener interfaces, experimental results from $\mathrm{T}$-sections strips were investigated. The application of the global-local approach for the analysis of larger structures was also demonstrated in comparison with experimental results for both single- and multi-stiffener panels. The results 
demonstrated that initiation of interlaminar damage, which triggered structural collapse in all cases, could be accurately predicted, and that the mechanisms promoting failure could also be identified. The use of the approach for the analysis of postbuckling composite structures has application for the design and certification of the next generation of aircraft.

\section{Acknowledgements}

The authors kindly acknowledge the financial support of: the European Commission, Priority Aeronautics and Space, Contract AST3-CT-2003-502723; the Australian Postgraduate Awards Scheme; the Cooperative Research Centre for Advanced Composite Structures (CRC-ACS); the German Academic Exchange Service (DAAD); the Italian Ministry of Foreign Affairs; and, the Australian Government under both the "Innovation Access Programme - International Science and Technology" and "International Science Linkages" established under the innovation statement, "Backing Australia's Ability". The work of the staff of the Aerospace Structures Lab., Technion, Aernnova Engineering Solutions and the Institute of Composite Structures and Adaptive Systems at DLR Braunschweig is also gratefully acknowledged.

\section{References}

1. Degenhardt $\mathrm{R}$, Rolfes $\mathrm{R}$, Zimmermann $\mathrm{R}$, Rohwer K. COCOMAT - improved material exploitation of composite airframe structures by accurate simulation of postbuckling and collapse. Compos Struct 2006; 73:175-8.

2. COCOMAT Home Page, www.cocomat.de; 2007.

3. Orifici AC, Herszberg I, Thomson RS, Weller T, Kotler A, Bayandor J. Failure in stringer interfaces in postbuckled composite stiffened panels. In: Proceedings of the 12th Australian International Aerospace Congress, Melbourne, Australia, 19-22 March 2007.

4. Orifici AC. Degradation models for the collapse analysis of composite aerospace structures. $\mathrm{PhD}$ thesis, Royal Melbourne Institute of Technology; 2007.

5. MSC.Marc User Manuals Version 2005r3, MSC.Software Corporation, Santa Ana, CA, 2006.
6. Tong L. An assessment of failure criteria to predict the strength of adhesively bonded double lap joints. J Reinf Plas Comp 1997;16:698-715.

7. Orifici, AC, Herszberg, I, Thomson, RS. Review of methodologies for composite material modelling incorporating failure. In: Proceedings of the 14th International Conference on Composite Structures, Melbourne, Australia, 14-16 November 2007.

8. Hashin Z. Failure criteria for unidirectional composites. J Appl Mech 1980;47:329-34.

9. Chang FK, Lessard LB. Damage tolerance of laminated composites containing an open hole and subject to compressive loadings: part I analysis. J Comp Mat 1991;25:2-43.

10. Herszberg I, Kotler A, Orifici AC, Abramovich $\mathrm{H}$, Weller T. Failure modes in loaded carbon/epoxy composite T-sections. In: Proceedings of the 12th Australian International Aerospace Congress, Melbourne, Australia, 19-22 March 2007.

11. Orifici AC, Shah SA, Herszberg I, Kotler A, Weller T. Failure analysis in postbuckled composite T-sections. In: Proceedings of the 14th International Conference on Composite Structures, Melbourne, Australia, 14-16 November 2007.

12. Orifici AC, Thomson RS, Ortiz de Zarate Alberdi I. Damage growth and collapse analysis of composite blade-stiffened structures. In: Proceedings of the 14th International Conference on Composite Structures, Melbourne, Australia, 14-16 November 2007.

13. Orifici AC, Thomson RS, Degenhardt R, Bayandor, J. Development of a finite element methodology for the collapse analysis of composite aerospace structures. In: Proceedings of ECCOMAS Thematic Conference on Mechanical Response of Composites, Porto, Portugal, 12-14 September 2007.

14. Degenhardt R, Kling A, Klein H, Hillger W, Goetting HC, Zimmermann R, Rohwer K, Gleiter A. Experiments on buckling and postbuckling of thin-walled CFRP structures using advanced measurement systems. International Journal of Structural Stability and Dynamics 2007;7(2):337-58. 